引用格式: 王珊珊, 张寒, 杨红强. 中国人造板行业的生命周期碳足迹和能源耗用评估 [J]. 资源科学, 2019, 41(3): 521-531. [Wang S S, Zhang H, Yang H Q. Carbon footprint and energy consumption based on life cycle assessment of wood-based panel industry in China[J]. Resources Science, 2019, 41(3): 521-531.] DOI: 10.18402/resci.2019.03.10

\title{
中国人造板行业的生命周期碳足迹和 能源耗用评估
}

\author{
王珊珊 ${ }^{1,2}$, 张 寒 ${ }^{2,3}$, 杨红强 $1,2,4$
}

(1. 南京林业大学经济管理学院, 南京 210037;

2. 国家林业局林产品经济贸易研究中心, 南京 210037 ;

3. 西北农林科技大学经济管理学院, 杨凌 712100 ;

4. 南京大学长江三角洲经济社会发展研究中心, 南京 210093)

\begin{abstract}
摘 要: 降低温室气体排放是应对气候变化的重要措施,基于生命周期分析的碳足迹评估被广泛应用于量化产 品的温室气体排放。在减排承诺背景下,林业部门在应对气候变化中具有重要贡献。中国作为世界最大的人造板 生产和出口国, 人造板行业的碳足迹和能源耗用问题, 是评价林业产业环境影响的重要领域。本文依据 ISO 14067 标准, 测度了中国胶合板、纤维板和刨花板行业“从摇篮到大门”系统界限的碳足迹, 通过对比国内外人造板行业的 能源耗用, 评估了中国人造板行业的节能潜力, 结合量化改进方案的减排效果, 提出了人造板行业减排和市场结构 改善的建议措施。研究发现: (1)中国现有人造板行业的碳足迹结构中, 纤维板最大 $\left(708.74 \mathrm{~kg} \mathrm{CO}_{2} \mathrm{e}\right)$, 胶合板最小 (312.08 $\left.\mathrm{kg} \mathrm{CO}_{2} \mathrm{e}\right)$, 创花板居中 (410.79 $\left.\mathrm{kg} \mathrm{CO}_{2} \mathrm{e}\right)$ 。其中原材料获取对碳足迹贡献最大, 化工材料如䐖醛树脂胶的生 产和使用是最主要的温室气体排放源; (2)对标国际标准和技术进步要求, 中国人造板行业的能源耗用可减少 $13.27 \%$ 47.99\% ; 3 用木质燃料替代化石能源, 对人造板行业的温室气体减排可实现 $11.53 \% \sim 42.30 \%$ 的提升空间。
\end{abstract}

关键词: 人造板行业; 生命周期分析; ISO 14067;温室气体;碳足迹;能源耗用; 中国

DOI :10.18402/resci.2019.03.10

\section{1 引言}

大气中温室气体 (Greenhouse Gas, GHG) 浓度 的不断增加导致全球气候变暖日益严峻, 威胁社会 经济的可持续发展。中国向国际社会承诺, 到 2020 年单位国内生产总值 $\mathrm{CO}_{2}$ 排放比 2005 年下降 $40 \%$ $45 \%^{[1]}$, 在此背景下, 许多产业部门都在积极寻求减 少 GHG 排放的途径与方法。

林业部门应对气候变化的贡献已得到广泛认 可, 木质林产品 (Harvested Wood Products, HWP) 的 碳储效益已被《京都议定书》规定为抵消国家 GHG
排放的重要手段 ${ }^{[2]}$ 。一方面, 森林生长阶段通过光 合作用, 以一种低成本高效益的方式吸收并减少大 气中的 $\mathrm{CO}_{2}$, 作为森林资源的延伸利用,生产和使用 木质林产品可视作“碳库”长期储碳, 减缓 $\mathrm{CO}_{2}$ 的释 放 ${ }^{[3]}$ 。另一方面, 已有诸多研究证明, 木质林产品的 生产和使用可有效替代能源密集型产品从而减少 GHG 排放 ${ }^{[4-6]}$ 。

尽管木质林产品的固碳减排可有效地减少气 候的依赖, 但其生产环节耗用能源仍不可避免地排

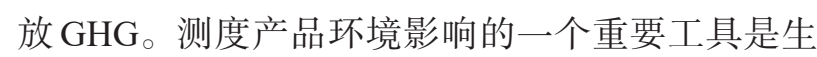

收稿日期: 2018-05-16 修订日期: 2018-11-27

基金项目: 江苏省“333 高层次人才工程”科研项目(BRA2018070); 国家社会科学基金重点项目(14AJY014); 江苏省研究生科研与实践创新计 划项目 (KYCX18_0974)。

作者简介: 王珊珊, 女, 江苏徐州人, 博士研究生, 助理研究员, 主要研究方向为气候变化与林产品碳足迹。E-mail: wssnjfu@outlook.com 通讯作者:杨红强,E-mail: yhqnfu@aliyun.com 
命周期分析法 (Life Cycle Assessment, LCA), LCA 的引人使得木质林产品碳流动的核算更为准确 ${ }^{[7]}$ 。 LCA 强调对某种产品从原材料获取到最终废弃整 个生命周期环境影响的综合评价, 评估系统界限内 物料及能源投人、产出造成的全球气候变暖、酸化 效应、光化学臭氧创造潜力、非生物性资源耗损、富 营养化、臭氧层损耗等的环境影响 ${ }^{[8]}$ 。作为评价产 品的环境影响的分析工具, 旨在推动和实现可持续 发展, LCA 已成为当今木质林产品及环境科学等领 域研究的热点 ${ }^{[9]}$ 。

基于过程分析的产品碳足迹(Carbon Footprint, CF) 计算, 是对 LCA 的直接应用 ${ }^{[10,11]}$, 聚焦于对全球 气候变暖的影响。碳足迹分析衡量产品在全生命 周期内直接和间接产生的 GHG 总量, 以二氧化碳当 量表述 $\left(\mathrm{CO}_{2} \text { equivalent, } \mathrm{CO}_{2} \mathrm{e}\right)^{[12]}$ 。基于 $\mathrm{LCA}$ 的碳足 迹评估在林产品碳科学研究中被广泛运用, 涉及多 个产品及行业。中间产品包括锯材 ${ }^{[1]}$ 、人造板如胶 合板 ${ }^{[13]} 、$ 纤维板 ${ }^{[14]} 、$ 创花板 ${ }^{[15-17]}$ 等, 最终产品涉及纸及 纸制品 ${ }^{[18-20]}$ 、木质家具 ${ }^{[21-23]}$ 、木结构建筑 ${ }^{[24-26]}$ 等。

作为综合、高效利用木材资源的主要途径, 人 造板已成为林业产业的支柱, 占林业第二产业总产 值的 $21 \%{ }^{[27]}$ 。人造板是以木材或其他植物为主要原 料, 经机械分离后施加胶粘剂加工而成的板材, 利 用秸秆、稻草等农业剩余物制造的人造板已得到推 广和使用 ${ }^{[28]}$ 。胶合板、纤维板和刨花板主导中国人 造板市场结构, 其产量占总产量的 $90.07 \%$, 其中胶 合板规模最大, 纤维板次之, 创花板最小, 2016年上 述三板产量分别为 1.78 亿 $\mathrm{m}^{3} 、 0.67$ 亿 $\mathrm{m}^{3} 、 0.27$ 亿 $\mathrm{m}^{3}$ 。应用领域涵盖家具 $(50 \%)$ 、建筑装饰 $(20 \%)$ 、包 装 $(9 \%)$ 、地板 $(8 \%)$ 、木门 $(7 \%)$ 和其他领域 $(6 \%)$ 。 中国是世界人造板生产和出口第一大国, 占全球总 供给的 $52.43 \%{ }^{[29]}$ 。

由于数据缺乏, 整体上当前中国林业产业碳足 迹研究尚欠缺。人造板行业的研究多聚焦单一板 材的碳足迹且数据较陈旧, 无法科学地反映行业实 际现状。因此, 本文首要目的在于测度中国人造板 行业碳足迹, 宏观把握和比较三大主要板材的 GHG 排放, 识别生命周期中各环节对环境影响的贡献 度; 其次, 通过与国外研究对比, 定量分析中国与世 界其他人造板生产大国对能源耗用的差异性; 最
后,设计减排方案并量化改进方案的减排效果, 提 出人造板行业的具体减排建议, 以有效发挥人造板 以及其他木质林产品在应对气候变化中的作用。

\section{2 研究方法}

现已开发的碳足迹评估方法主要基于以下三 个核心标准: PAS $2050^{[30,31]}$ 、GHG Protocol ${ }^{[32]}$ 和 ISO $14067^{[33]}$ 。相对 PAS 2050 和 GHG Protocol, ISO 14067 不考虑林产品碳储存抵消碳排放的贡献,而 单独报告碳储量。因板材内部储量不一, 应用 ISO 14067 可客观地比较不同产品的碳足迹,故本文依 据 ISO 14067 标准核算人造板碳足迹。考量的 GHG 界定为 $\mathrm{CO}_{2}$ 、甲烷和氧化亚氮。

\section{1 生命周期阶段}

\subsection{1 系统界限及功能单位}

功能单位的选取是评估碳足迹的基础, 本文定 义功能单位为生产 $1 \mathrm{~m}^{3}$ 胶合板、纤维板和创花板 ${ }^{[34]}$ 。 系统界限决定何种过程应包含在研究范围内 ${ }^{[35]}$ 。人 造板是中间产品, 下游产品使用较难追踪且最终处 理方式存在很大的不确定性, 故本文系统界限定义 为“从摇篮到大门” (图 1), 涵盖从上游原料获取到 工厂生产完成运出分配的所有工序, 细分为以下三 个主要子系统: (1)原材料获取; (2)原材料运输; (3)现 场生产。

(1)原材料获取子系统。该子系统涵盖木质原 材料获取和附属化工材料获取两部分。不同板材 对木质原材料要求不同,胶合板对原材料要求较 高,一般为大径原木;纤维板、刨花板对原材料的要 求则较低,可以是原木、“三剩物” (采伐剩余物、造 材剩余物、加工剩余物）、次小薪材、秸秆、甘蔗渣 等。林业生产过程的 GHG 排放源包括: 修整土地、 伐木、运输木材等消耗燃油产生的 GHG; 施用化肥、 农家肥等排放的 GHG; 喷酒农药、除草剂排放的 GHG。附属原材料主要是化工材料,包括胶黏剂 (脲醛树脂胶)、固化剂(氯化铵)和防水剂(石蜡)以 及面粉等。生产化工材料造成的 GHG 排放也计人 原材料获取子系统。

(2)原材料运输子系统。该子系统是指木质原 料及附属原料从产地运送到人造板加工厂的过程， 其间耗用能源产生的 GHG 计人系统界限。此外,企 业外购木质废料用于能源生产, 木质废料运输过程 


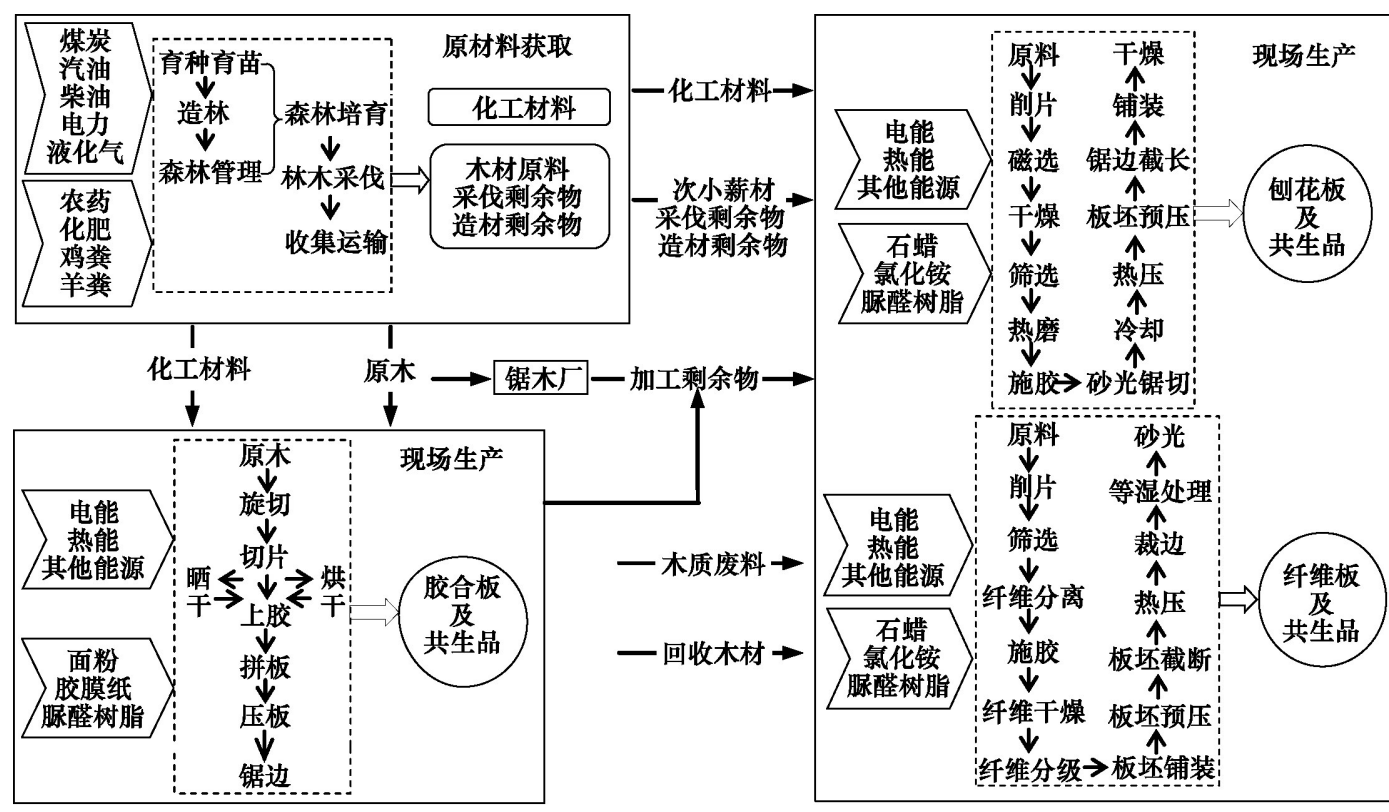

图例 $\square$ 能源输入 $\rightarrow$ 生产工序 $\rightarrow$ 原材料运输 $\Rightarrow$ 产品产出 $\square$ 原材料 $\bigcirc$ 人造板及共生品

图 1 本项研究的系统边界:基于“从摇篮到大门”的生命周期评估

Figure 1 System boundary of the present study based on cradle-to-gate life cycle assessment

排放的 GHG 均计人原材料运输子系统。

(3) 现场生产子系统。胶合板的主要生产工序 包括备料、原木旋切、单板干燥、单板整理、涂胶热 压、锯边砂光和成品人库等; 纤维板生产系统涉及 的主要工序包括备料、纤维制备、板坏成型、热压及 后处理等;创花板的主要生产工序包括备料、干燥 分选、施胶、铺装热压和锯边砂光等。

利用取舍原则通过设置量化标准, 排除与产品 生命周期各环节相关性较小的材料、能源投人以及 环境产出 ${ }^{[36]}$ 。ISO 14067 规定排除对最终结果没有 显著影响的过程或材料,但未给出具体的取舍原 则。本文参考 ISO 14040 , 设置 “ $1 \%$ ”的取舍原则, 即 材料或能源低于总材料或总能源的 $1 \%$, 或某一过 程排放的 GHG 对总结果的贡献度低于 $1 \%$, 则从系 统界限排除。

\subsection{2 分配方法}

人造板生产是典型的多功能过程, 即其生产系 统是多产出的系统, 由人造板材及共生品等为多个 产品共享 ${ }^{[37]}$ 。以胶合板生产为例, 除产出所需的胶 合板外, 共生品如锯屑等边角料用于外售, 具有一 定的经济价值。当多个产品或功能共享相同的过 程时,采用分配方法划分多个产品之间的环境负
荷,包括物流、能流和环境影响 ${ }^{[17]}$ 。依据 FPInnovations Wood Product Category Rules 2011 (PCR $)^{[38]}$, 质 量是分配木质林产品环境影响最合适的参数, 因此 本文基于人造板及其共生品的质量值分配能源消 耗量及 $\mathrm{GHG}$ 排放。

平均而言,创花板和纤维板的原材料结构中, “三剩物”约占 $75 \%$, 次小薪材约为 $20 \%$, 回收木材等 约为 $5 \%{ }^{[39]}$ 。“三剩物” 来源于森林经营采伐、上游木 材加工等过程, 胶合板生产系统产出的加工剩余物 也为纤维板和刨花板的生产供应原料。因此,这些 剩余物作为共生品参与上游森林经营及木材加工 环节的环境影响分配。

\section{2 数理模型及数据源}

碳足迹是产品生命周期各个阶段所有 $\mathrm{GHG}$ 排 放的总和,也包括购买能源产生的隐含排放 ${ }^{[40]}$, 各阶 段 GHG 排放量通常以活动数据与相应排放因子的 乘积表述 ${ }^{[4]}$, 具体的数理模型如下:

$$
G=\sum_{i=0}^{n}\left(M_{i} \times E F_{i 1}\right)+\sum_{i=0}^{n}\left(E_{i} \times E F_{i 2}\right)+\sum_{i=0}^{n}\left(T_{i} \times D_{i} \times E F_{i 3}\right)
$$

式中: $G$ 为产品生命周期碳足迹 $\left(\mathrm{kg} \mathrm{CO}_{2} \mathrm{e}\right) ; M_{i}$ 为生 产活动中消耗的第 $i$ 类物质的活动数据 $(\mathrm{kg}) ; E F_{i 1}$ 为 
第 $i$ 类材料的排放因子 $\left(\mathrm{kg} \mathrm{CO}_{2} \mathrm{e} / \mathrm{kg}\right) ; E_{i}$ 为生产活动 中消耗的第 $i$ 类能源活动数据, 折算标准煤 $(\mathrm{kgce})$; $E F_{i 2}$ 为第 $i$ 类能源折算标准煤的排放因子 $\left(\mathrm{kg} \mathrm{CO}_{2} \mathrm{e} /\right.$ $\mathrm{kgce}) ; T_{i}$ 为第 $i$ 类交通工具运输产品的实物量 $(\mathrm{kg})$; $D_{i}$ 为第 $i$ 类交通工具的运输距离 $(\mathrm{km}) ; E F_{i 3}$ 为第 $i$ 类 交通运输工具的排放因子 $\left(\mathrm{kg} \mathrm{CO}_{2} \mathrm{e} / \mathrm{kg} \cdot \mathrm{km}\right)$ 。

本文采取现场调研和文献数据相结合的方法, 建立中国人造板“从摇篮到大门”系统界限的生命 周期清单。具体数据来源为: (1)国家统计局、国家 林业局等发布的统计年鉴及报告; (2)公开发表的研 究论文和研究报告; (3)权威的中国本土生命周期基 础数据库; (4)企业调研数据源。各项数据质量较 高, 能够反映中国人造板行业的整体技术水平 (表 1$)$ 。

\section{3 清单分析}

生命周期清单 (Life Cycle Inventory, LCI) 涉及 产品系统的相关输人和输出, 整理对环境产出相关 性较大的物料、能量输人 ${ }^{[51]}$ 。本文建立了中国人造 板行业生命周期清单, 明确了系统界限内的资源投 人和环境产出。

\subsection{1 原材料获取}

木质原料的获取经由森林种植管理和林木采 运的森林经营阶段, 消耗化石能源、化肥、杀虫剂等 产生的 GHG 计人系统界限。生产 $1 \mathrm{~kg}$ 原木产生的 GHG 排放量为 $0.15 \mathrm{~kg} \mathrm{CO}_{2} \mathrm{e}$, 生产 $1 \mathrm{~kg}$ 脲醛树脂胶 和 $1 \mathrm{~kg}$ 面粉排放的 $\mathrm{GHG}$ 分别为 $2.39 \mathrm{~kg} \mathrm{CO} \mathrm{e}$ 和 1 $\mathrm{kg} \mathrm{CO} \mathrm{e}_{\circ}$

\subsection{2 原材料运输}

运输阶段包括木质原料及附属材料的运输, 木 质原料采用重型卡车运输方式, 到人造板生产厂的 平均运距为 $300 \mathrm{~km}$; 用于能源生产的木质废料运距 为 $50 \mathrm{~km}$, 其余原材料运输阶段为柴油汽车运输, 因 数据获取较难, 现根据2016年中国货物平均运距视 为 $183 \mathrm{~km}$ 。

\subsection{3 现场生产}

表 2 整理了人造板现场生产阶段消耗的原料及 能源, 能源类型主要是热能和电能。胶合板现场生 产总耗能为 $1515.09 \mathrm{MJ}$, 其中热能主要用于纤维制 备、调胶施胶和成型热压等工序。纤维板生产阶段 用热环节主要为热磨、纤维干燥、热压工序, 总能耗 为 $6309.76 \mathrm{MJ}$ 。刨花板现场生产总能耗为 1764.20 MJ, 用热工序主要是干燥、制胶、石蜡融化和热压 等。PCR 针对木质燃料燃烧提出“碳中和” 的假设, 即木质燃料产生的 $\mathrm{CO}_{2}$ 等价于森林碳汇阶段吸收的 量, 因此,本文排除木质燃料产生的 $\mathrm{CO}_{2}$ 。

\section{3 结果及讨论}

\section{1 碳足迹结果}

在所界定的“从摇篮到大门”系统内分析人造 板行业碳足迹,结果显示, 纤维板生命周期的碳足 迹最大 $\left(708.74 \mathrm{~kg} \mathrm{CO}_{2} \mathrm{e}\right)$, 胶合板最小 $(312.08 \mathrm{~kg}$ $\left.\mathrm{CO}_{2} \mathrm{e}\right)$, 创花板居中 $\left(410.79 \mathrm{~kg} \mathrm{CO}_{2} \mathrm{e}\right)$, 纤维板的碳足 迹分别是胶合板和刨花板的 2.27 倍和 1.73 倍 (图 2)。纵向各阶段分析: 原材料获取阶段,纤维板和

表 1 所需活动数据及排放因子的数据源

Table 1 Sources of activity data and emission factor for quantifying carbon footprint

\begin{tabular}{|c|c|c|}
\hline 生命周期系统 & 活动数据数据来源 & 排放因子数据来源 \\
\hline \multicolumn{3}{|l|}{ 原材料获取 } \\
\hline 木质原材料 & 陈莎等 $(2014)^{[19]}$ & González-García 等(2009) ${ }^{[46]}$ \\
\hline 艮醛树脂胶 & 胶合板:企业调研 & 张运明(2013) $)^{[47]}$ \\
\hline 面粉 & 纤维板/创花板: 时兰翠 $(2012)^{[42]}$ & 张雄智等(2018) ${ }^{[48]}$ \\
\hline \multicolumn{3}{|l|}{ 原材料运输 } \\
\hline 运输距离 & $\begin{array}{l}\text { 木质原材料:钱小瑜 }(2009)^{[43]} \\
\text { 附属原材料: }\end{array}$ & $\operatorname{CLCD}(2010)^{[49]}$ \\
\hline 能源耗用 & $\begin{array}{l}\text { 木质废料:张方文 }(2017)^{[44]} \\
\text { 其余材料:国家统计局 }(2017)^{[45]}\end{array}$ & \\
\hline \multicolumn{3}{|l|}{ 现场生产 } \\
\hline 能源耗用 & $\begin{array}{l}\text { 胶合板:企业调研 } \\
\text { 纤维板/创花板: 时兰翠 }(2012)^{[42]}\end{array}$ & 国家林业局 (2012) $)^{[50]}$ \\
\hline
\end{tabular}


表 $21 \mathbf{m}^{3}$ 人造板现场生产投入产出清单

Table 2 Input-output inventory for the production of $1 \mathrm{~m}^{3}$ of wood-based panel

\begin{tabular}{|c|c|c|c|c|c|c|}
\hline \multirow{2}{*}{$\frac{\text { 人造板 }}{\text { 投人 }}$} & \multicolumn{2}{|c|}{ 胶合板 } & \multicolumn{2}{|c|}{ 纤维板 } & \multicolumn{2}{|c|}{ 创花板 } \\
\hline & 名称 & 用量 & 名称 & 用量 & 名称 & 用量 \\
\hline \multirow[t]{4}{*}{ 原料 } & 原木 & $615.00 \mathrm{~kg}$ & 木质原材料 & $892.30 \mathrm{~kg}$ & 木质原材料 & $800.00 \mathrm{~kg}$ \\
\hline & 脲醛树脂胶 & $25.00 \mathrm{~kg}$ & 艮醛树脂胶 & $110.00 \mathrm{~kg}$ & 艮醛树脂胶 & $68.00 \mathrm{~kg}$ \\
\hline & 面粉 & $7.50 \mathrm{~kg}$ & 石蜡 & $9.50 \mathrm{~kg}$ & 石蜡 & $6.33 \mathrm{~kg}$ \\
\hline & 胶膜纸 & $1.50 \mathrm{~kg}$ & 氯化铵 & $3.80 \mathrm{~kg}$ & 氯化铵 & $1.10 \mathrm{~kg}$ \\
\hline \multirow[t]{4}{*}{ 能源 } & 电力 & $2.75 \mathrm{kWh}$ & 电力 & $755.83 \mathrm{kWh}$ & 电力 & $339.44 \mathrm{kWh}$ \\
\hline & 蒸汽 & $400.00 \mathrm{~kg}$ & 木质废料 & $245.50 \mathrm{~kg}$ & 蒸汽 & $124.00 \mathrm{~kg}$ \\
\hline & & & 燃煤 & $51.98 \mathrm{~kg}$ & 压缩空气 & $64.62 \mathrm{~m}^{3}$ \\
\hline & & & 压缩空气 & $88.83 \mathrm{~m}^{3}$ & & \\
\hline 产出 & \multicolumn{2}{|c|}{ 胶合板 (680.00 kg/m³) } & \multicolumn{2}{|c|}{ 纤维板 $\left(750.00 \mathrm{~kg} / \mathrm{m}^{3}\right)$} & \multicolumn{2}{|c|}{ 创花板 (700.00 kg/m³) } \\
\hline
\end{tabular}

注:木质废料热能为 $9.77 \mathrm{MJ} / \mathrm{kg}$ 。

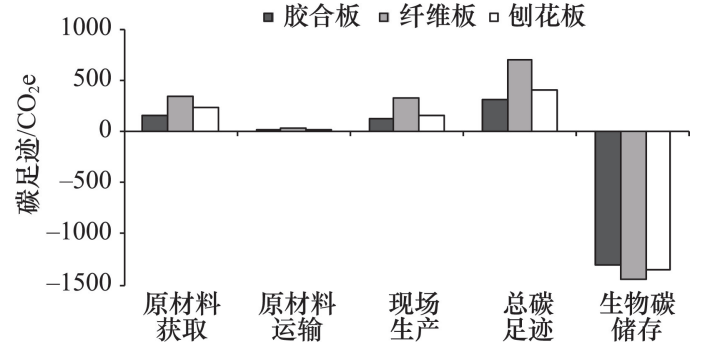

图 2 人造板“从摇篮到大门”生命周期的碳足迹

Figure 2 Cradle-to-gate life cycle carbon footprint of wood-based panels 创花板排放的 GHG 均高于胶合板, 主要原因是纤维 板和刨花板的原料参与上游森林管理和木材加工 的环境负荷的分配。原材料运输阶段, 由于纤维板 和刨花板原料来源广, 运输过程三板碳排放大小顺 序为: 纤维板 $>$ 创花板 $>$ 胶合板。现场生产阶段, 纤 维板的能源耗用远高于刨花板和胶合板, 故其 GHG 排放最高, 其次是刨花板, 最后是胶合板, 最大者是 最小者的 2.54 倍。

根据 ISO 14067 , 木材储存的生物碳应以负值 形式单独报告。人造板中的平均碳含量为 $52.40 \%{ }^{[14]}$, 基于这一参数, $1 \mathrm{~m}^{3}$ 胶合板、纤维板和创花板中生物 碳储存量分别为 $-1307.69 \mathrm{~kg} \mathrm{CO} \mathrm{CO}_{2} \mathrm{e}-1442.31 \mathrm{~kg}$ $\mathrm{CO}_{2} \mathrm{e}$ 和 $-1346.16 \mathrm{~kg} \mathrm{CO}_{2} \mathrm{e}$ 。

横向单个板材的生命周期分析, 胶合板的 GHG 排放主要集中在原材料获取阶段, 占总碳足迹的 $51.27 \%$, 尤其是木质原材料的获取及脲醛树脂胶生 产。相对来说, 运输阶段 GHG 排放较低, 仅占 $6.17 \%$ 。纤维板生命周期中, 原材料获取的贡献最
大 $(48.14 \%)$, 现场生产对总碳足迹的贡献达到 $47.59 \%$ 。刨花板原材料获取阶段总排放占比 $56.64 \%$, 远高于运输阶段和现场生产的 GHG 排放。

表 3 反映了胶合板、纤维板和刨花板生命周期 各阶段碳足迹占总碳足迹的比重。三板生命周期 各阶段 GHG 排放大小趋势一致, 即 : 原材料获取 $>$ 现场生产>原材料运输。脲醛树脂胶的生产和使用 对原材料获取阶段总碳足迹的贡献最大, 分别占比 $19.15 \%$ 、37.09\% 和 $39.56 \%$ 。胶水是木质复合材料 不可或缺的组成部分, 与其他人造板生产国相比, 中国生产 $1 \mathrm{~m}^{3}$ 纤维板消耗 $110 \mathrm{~kg}$ 脲醛树脂胶, 而西 班牙、巴西、美国和加拿大则分别仅需 $44.44 \mathrm{~kg}$ 、

表 3 胶合板、纤维板和刨花板生命周期各阶段的 碳足迹比重

Table 3 Proportion of the carbon footprint for plywood, fiberboard and particleboard in different life cycle stages

\begin{tabular}{|c|c|c|c|c|}
\hline \multirow{2}{*}{\multicolumn{2}{|c|}{ 生命周期阶段 }} & \multicolumn{3}{|c|}{ 占总碳足迹的百分比/\% } \\
\hline & & 胶合板 & 纤维板 & 创花板 \\
\hline \multirow{3}{*}{$\begin{array}{c}\text { 原材料 } \\
\text { 获取 }\end{array}$} & 木质原料 & 29.72 & 11.04 & 17.08 \\
\hline & 脲醛树脂胶 & 19.15 & 37.09 & 39.56 \\
\hline & 其他原材料 & 2.40 & 0.00 & 0.00 \\
\hline \multicolumn{2}{|c|}{ 原材料运输 } & 6.17 & 4.28 & 6.21 \\
\hline \multicolumn{2}{|c|}{ 现场生产 } & 42.57 & 47.59 & 37.15 \\
\hline \multicolumn{2}{|r|}{ 合计 } & 100.00 & 100.00 & 100.00 \\
\hline
\end{tabular}

注: 胶合板生命周期,胶膜纸生产的碳足迹按取舍原则被略 去; 纤维板生命周期, 石蜡和氯化铵生产的碳足迹按取舍原则被略 去; 创花板生命周期, 石蜡和氯化铵生产的碳足迹按取舍原则被 略去。 
$70.30 \mathrm{~kg} 、 83.30 \mathrm{~kg}$ 和 $85.3 \mathrm{~kg}^{[51-54]}$ 。

\section{2 现场生产子系统能源耗用对比}

中国是人造板生产大国, 但不是生产强国 ${ }^{[55]}$ 。 通过碳足迹核算挖掘碳减排潜力,可全面了解生产 过程能源及物料使用效率,有利于提高使用效率并 降低成本, 从而开发出最具成本有效性的生产方 案。为客观地评价中国人造板行业的能源消耗现 状, 本文将三板现场生产的能耗量与国外主要人造 板生产国能耗量进行比较。在能源结构方面, 中国 人造板与国外板材接近, 以热能中心供热为主, 电 能等用于生产设备供电。

表 4 反映了人造板生产国不同板材的能耗量。 由于统计研究所采用的系统界限不一, 绝大多数研 究 ${ }^{[17,56,57,59]}$ 建立 “从摇篮到大门” 的系统模型, 仅部分

\section{表 4 中国人造板现场生产子系统能源耗用与国外相关板} 材能源耗用对比

Table 4 Comparison of energy consumption for on-site manufacturing in China and internationally

\begin{tabular}{|c|c|c|c|}
\hline 板材 & $\begin{array}{l}\text { 研究 } \\
\text { 地区 }\end{array}$ & $\begin{array}{c}\text { 能源耗用/ } \\
\left(\mathrm{MJ} / \mathrm{m}^{3}\right)\end{array}$ & $\begin{array}{l}\text { 数据源 } \\
\text { 及年份 }\end{array}$ \\
\hline \multirow[t]{7}{*}{ 胶合板 } & 智利 & 4944.00 & Meil等 $(2010)^{[5]]}$ \\
\hline & 美国 东南部 & 4640.00 & Kaestner $(2015)^{[57]}$ \\
\hline & 西北部 & 4340.00 & \\
\hline & 芬兰 & 4398.00 & Meil等 $(2010)^{[56]}$ \\
\hline & 瑞典 & 4398.00 & \\
\hline & 加拿大 & 1935.35 & \\
\hline & 中国 & 1515.09 & 本项研究 \\
\hline \multirow[t]{9}{*}{ 纤维板 } & 美国 & 10723.00 & Wilson $(2010)^{[14]}$ \\
\hline & 日本 & 7234.44 & Nakano 等 $(2018)^{[34]}$ \\
\hline & 中国 & 6309.76 & 本项研究 \\
\hline & 加拿大 & 6229.92 & Meil 等 $(2010)^{[56]}$ \\
\hline & 伊朗 & 5267.74 & Kouchakipenchah等 \\
\hline & & & $(2016)^{[58]}$ \\
\hline & 智利 & 4119.00 & Meil等 $(2010)^{[56]}$ \\
\hline & 北欧 & 3857.00 & \\
\hline & 巴西 & 3281.43 & Piekarski等 $(2017)^{[53]}$ \\
\hline \multirow[t]{8}{*}{ 刨花板 } & 巴基斯坦 & 5457.50 & Hussain等(2017) $)^{[17]}$ \\
\hline & 智利 & 4119.00 & Meil等 $(2010)^{[56]}$ \\
\hline & 北欧 & 3857.00 & \\
\hline & 日本 & 2943.11 & Nakano 等 $(2018)^{[34]}$ \\
\hline & 加拿大 & 2940.55 & Meil等 $(2010)^{[56]}$ \\
\hline & 美国 & 2299.00 & Wilson $(2010)^{[15]}$ \\
\hline & 中国 & 1764.20 & 本项研究 \\
\hline & 巴西 & 1530.14 & Silva等 $(2013)^{[59]}$ \\
\hline
\end{tabular}

研究 ${ }^{[22,58]}$ 聚焦现场生产, 建立“从大门到大门”的系 统界限。还有少数研究 ${ }^{[14,15,34]}$ 基于双重系统界限分 析了不同生命周期的环境产出。因此,表 4 仅整理 参引的国内外研究中涉及现场生产子系统的能 耗。排除统计口径的不一致, 以及排放系数的差异 等原因,中国胶合板在所对比的国家中能耗最小。 其原因在于胶合板作为中国人造板市场的主体,经 过多年淘汰落后产能,已具备充分的国际行业竞争 和技术优势 ${ }^{[39]}$ 。巴西的纤维板和创花板在所对比的 国家中能耗投人最小, 对标巴西的能耗量, 中国人 造板行业尚可减少 $13.27 \%$ 47.99\%的能源消耗。

国内同类研究多聚焦于单一板材的节能减排, 本文评估人造板行业整体的碳足迹和能源耗用,分 析各板材生命周期碳足迹的分布特征。同样地,排 除统计口径的不一致, 以及排放系数的差异等原 因,本文得出的胶合板现场生产子系统的能耗量低 于王丽等 ${ }^{[00]}$ 的研究结论 $\left(6000 \mathrm{MJ} / \mathrm{m}^{3}\right)$, 原因在于其 研究中计量木质燃料排放的 $\mathrm{CO}_{2}$, 而本文引入“碳中 和”的概念, 不考虑这部分的排放。本文所涉及的胶 合板生产企业, 其能源结构仅由蒸汽和电力构成, 能 源结构不同。纤维板的能耗量高于胡广斌等 ${ }^{[1]}$ 的研 究结论 (5115.42 5485.87 MJ/m³), 其原因在于案例 企业均属行业领先, 能耗水平达《LY/T 1451-2008纤 维板生产综合能耗》的优秀指标。鉴于中小企业主 导纤维板市场, 本文则计量行业平均能耗。刨花板 的能耗量高于张方文等 ${ }^{[62]}$ 的研究结论 $(733.18 \mathrm{MJ} /$ $\left.\mathrm{m}^{3}\right)$, 主要由于研究对象 (定向刨花板)、数据源 $(\mathrm{Ga}-$ $\mathrm{Bi}$ 数据库)和能源结构 (电力和柴油)的不同。与国 内研究对比分析, 本文研究结果在数据适用度及代 表性方面更具普适性。

整体来看, 中国人造板行业集中度低,企业规 模较小。行业布局较分散,规模最大的企业市场占 有率仅不到 $1 \%$ 。胶合板行业, 中小企业占比 $75 \%$ 左 右; 纤维板行业, $90 \%$ 以上为中小型企业; 而刨花板 行业的中小型企业占比更达 $98 \%$ 以上。由此造成 生产成本高且能源消耗大等问题, 因此, 中国人造 板行业还具有很大的节能空间。

\section{3 改进方案的温室气体减排效果分析}

国外人造板行业多采用木质燃料供热。木质 燃料是一种可再生燃料, 可有效替代化石能源, 从 
而能改善产品生产过程中的环境排放 ${ }^{[63]}$ 。 Kouchakipenchah 等 ${ }^{[58]}$ 研究发现, 伊朗刨花板生产过 程使用木质燃料替代化石能源燃烧供热, 显著地降 低了对环境的影响。中国胶合板、纤维板和刨花板 生产消耗热能分别为: $1505.20 \mathrm{MJ} 、 3588.77 \mathrm{MJ}$ 和 $542.22 \mathrm{MJ}$, 由蒸汽、原煤等实现。改进方案为: 设计 所有热能均由木质燃料提供。根据张南等 ${ }^{[6]}$ 针对木 质家具生态设计方案减排效果公式, 本文提出的改 进方案对 GHG 减排效果量化公式为:

$$
E F=\frac{G H G_{\mathrm{BS}}-G H G_{\mathrm{IS}}}{G H G_{\mathrm{BS}}} \times 100 \%
$$

式中: $E F$ 为减排效果 $(\%) ; G H G_{\mathrm{BS}}$ 为人造板基准碳 足迹 $\left(\mathrm{kg} \mathrm{CO}_{2} \mathrm{e}\right) ; G H G_{\mathrm{IS}}$ 为改进方案碳足迹 $(\mathrm{kg}$ $\mathrm{CO}_{2} \mathrm{e}$ )。按方案设计, 使用木质燃料供热, 胶合板的 碳足迹为 $180.08 \mathrm{~kg} \mathrm{CO}_{2} \mathrm{e}$, 减排效果最显著, 减排约 $42.30 \%$ 。纤维板和创花板碳足迹下降较大, 替代后 碳足迹分别为 $605.78 \mathrm{~kg} \mathrm{CO}_{2} \mathrm{e}$ 和 $363.41 \mathrm{~kg} \mathrm{CO}_{2} \mathrm{e}$, 有 效减排 $14.53 \%$ 和 $11.53 \%$ 。总体来看, 使用木质燃料 替代化石能源的减排效果显著。

\section{4 人造板碳足迹评估核心要素与研究前瞻}

人造板碳足迹评估 “从摇篮到坟墓” 的系统界 限涵盖原材料获取、原材料运输、现场生产、产品分 配和使用及产品废弃处理全过程。由于数据缺乏, 本文仅考虑原材料获取到现场生产的生命周期, 忽 略了产品分配及废弃处理。参考 Garcia 等 ${ }^{[16]}$ 和 San$\operatorname{din}$ 等 $^{\left[{ }^{65]}\right.}$ 的研究,使用阶段不考虑能源耗用排放的碳 足迹, 对废弃处理方式 (填埋、燃烧或回收)进行情 境假设, 建立全生命周期的碳足迹评估模型。在未 来产品碳足迹评估研究中, 基于实际情况引人情境 假设, 并对废弃处理方式进行敏感度分析, 构建从 原材料获取到最终处理的全生命周期模型, 系统评 估中国人造板及林业产业的碳足迹。

基于建立的系统模型, 本文采取现场调研获取 直接数据和通过文献、产业报告及国家统计资料获 取二手数据相结合的方法构建人造板生命周期清 单。ISO 14067 按照数据来源将清单数据分为两 类, 即: 来自企业和供应链的原始数据和除原始数 据之外的次级数据。数据质量上原始数据优于次 级数据。本文中木质原材料获取阶段的排放因子 采用国外数据, 部分地降低了研究结果的代表性。
碳足迹作为评价全球气候变暖的指标已被广 泛应用,但实现全面综合的产品生命周期环境影响 评估,还涉及酸化效应、光化学臭氧创造潜力、非生 物性资源耗损、富营养化、臭氧层损耗等多个环境 影响方面。未来将通过构建人造板生命周期环境 影响的综合评价指标体系,发掘人造板行业环境可 持续性的潜力。

\section{4 结论及建议}

林业是应对气候变化国家战略的重要组成部 分,减少林业排放是实现林业部门对气候变化贡献 的有效手段。人造板行业不仅是林业产业中的支 柱产业,在国际贸易中也占据主导地位。分析人造 板的环境影响,做好节能工作,对发挥林业的减排 贡献有借鉴意义。为综合评估中国人造板“从摇篮 到大门”系统界限 GHG 排放及能源耗用, 利用生命 周期分析方法测度了三大主要板材的碳足迹,并进 一步量化改进方案的减排效果, 主要结论如下:

(1) 人造板行业。该行业中, 三板的碳足迹 从大到小依次为: 纤维板>刨花板>胶合板。1 $\mathrm{m}^{3}$ 胶 合板、纤维板和刨花板中的生物碳储存量分别 为 $-1307.69 \mathrm{~kg} \mathrm{CO}_{2} \mathrm{e} 、-1442.31 \mathrm{~kg} \mathrm{CO}_{2} \mathrm{e}$ 和-1346.16 $\mathrm{kg} \mathrm{CO}_{2} \mathrm{e}$ 。三大板材生命周期各阶段 $\mathrm{GHG}$ 排放大小 趋势一致, 即 “原材料获取 $>$ 现场生产 $>$ 原材料运 输”。化工材料, 尤其是脲醛树脂胶的生产和使用 是最大的 GHG 排放源, 对总碳足迹的贡献达到 $19.15 \%$ 39.56\% , 且高于国外同类板材的使用量和 排放量。

(2)对标国外市场。由于中国人造板行业的集 中度低且企业规模较小、产业布局较分散等原因, 现场生产能耗与国外市场差异性较大,生产成本高 于国外市场, 中国人造板行业还具有很大的节能潜 力。对标巴西等在板材现场生产过程中能耗投人 较小的国家, 尚可减少 $13.27 \%$ 47.99\%的能源耗用。

(3) 燃料替代。采用木质燃料替代化石能源的 改进方案, 对人造板行业的 GHG 减排效果显著, 可 实现 $11.53 \% \sim 22.30 \%$ 的提升空间。

综上所述, 虽然中国人造板行业发展进步较 快, 但其能源结构仍有待调整优化。基于木质燃料 存储的碳有效抵消 $\mathrm{CO}_{2}$ 排放的特性,大力开发木质 
燃料有助于实现 GHG 减排。同时, 回收使用人造板 生产过程产生的木质废料有助于减少运输阶段的 能源耗用, 从而降低全生命周期的碳足迹。人造板 行业能源结构的优化转型, 应坚持木质燃料等的可 持续利用。

中国人造板市场结构也有改善空间, 现行市场 忽视了刨花板的发展潜力。根据中国林业统计 ${ }^{[27]}$, 2011-2016 年刨花板的消费量平均增长 $18.54 \%$, 超 过胶合板和纤维板的平均增速 (分别为 $17.81 \%$ 和 $7.95 \%$ )。对标欧美市场, 创花板是欧美市场的主导 产品, 比重达 $50 \%$ 以上。与世界人造板产业格局不 同, 中国刨花板仅占 $8.82 \%$, 市场规模过小。刨花板 是中国人造板国际贸易中唯一进口量大于出口量 的人造板材, 进口量高达出口量的 3 倍。由于其不 消耗大径材,在木材资源日益枯竭的现实背景下， 发展刨花板有利于缓解林木资源匮乏的严峻性。 同时, 创花板下游产业刚需旺盛, 可作为家具和室 内装修的主要材料和承重部件, 部分替代胶合板和 纤维板的使用。此外, 碳足迹评估结果显示, 创花 板在应对气候变化中有很大的减排潜力。其碳储 量高于胶合板且碳足迹低于纤维板,能源耗用也远 低于纤维板。在未来的产业结构调整中考虑进刨 花板的减排潜力, 发展优质刨花板的生产和使用, 符合中国人造板产业结构升级方向。在此形势下， 刨花板行业应致力于提高产品质量和降低生产能 耗, 同时调整优化生产能力构成, 积极参与市场竞 争,推动人造板行业在生态、环境、社会和经济等方 面的可持续协调发展。

\section{参考文献(References):}

[1] An J, Xue X. Life cycle carbon footprint analysis of magnesia products[J]. Resources, Conservation and Recycling, 2017, 119: 4-11.

[2] Intergovernmental Panel on Climate Change (IPCC). 2013 Revised Supplementary Methods and Good Practice Guidance Arising from the Kyoto Protocol[R]. Geneva: IPCC, 2014.

[3 ] Pan Y D, Birdsey R A, Fang J Y, et al. A large and persistent carbon sink in the world's forests[J]. Science, 2011, 333(6045): 988993.

[ 4] Sathre R, O' Connor J. Meta-analysis of greenhouse gas displacement factors of wood product substitution[J]. Environmental Science and Policy, 2010, 13(2): 104-114.
[5] Kutnar A, Hill C. Assessment of Carbon Foot Printing in the Wood Industry[A]. Muthu S. Assessment of Carbon Footprint in Different Industrial Sectors[M]. Singapore: Springer, 2014.

[6] 张小标, 杨红强. 基于 GFPM 的中国林产品碳储效能及碳库结 构动态预测 [J]. 资源科学, 2015, 37(7): 1403-1413. [Zhang X B, Yong H Q. Dynamic projection of storage efficiency and carbon pool structure of China's harvested wood products based on GFPM[J]. Resources Science, 2015, 37(7): 1403-1413. ]

[7] 陈家新, 杨红强. 全球森林及林产品碳科学研究进展与前瞻 [J]. 南京林业大学学报(自然科学版), 2018, 42(4): 1-7. [Chen J $\mathrm{X}$, Yang H Q. The advances and frontiers in global forest and harvested wood products carbon science[J]. Journal of Nanjing Forestry University (Nature Sciences), 2018, 42(4): 1-7. ]

[8] International Organization for Standardization (ISO). ISO 14040: Environmental Management- Life Cycle Assessment: Principles and Framework[R]. Geneva: ISO, 2006.

[9] González-García S, Feijoo G, Widsten P, et al. Environmental performance assessment of hardboard manufacture[J]. International Journal of Life Cycle Assessment, 2009, 14(5): 456-466.

[10] 刘韵, 师华定, 曾贤刚. 基于全生命周期评价的电力企业碳足 迹评估: 以山西省吕梁市某燃煤电厂为例 $[J]$. 资源科学, 2011, 33(4): 653-658. [Liu Y, Shi H D, Zeng X G. A life-cycle carbon footprint assessment of electric power companies[J]. Resources Science, 2011, 33(4): 653-658. ]

[11] Martínez-Alonso C, Berdasco L. Carbon footprint of sawn timber products of Castanea sativa, Mill. in the north of Spain[J]. Journal of Cleaner Production, 2015, 102(9): 127-135.

[12] Laurent A, Olsen S I, Hauschild M Z. Carbon footprint as environmental performance indicator for the manufacturing industry [J]. CIRP Annals-Manufacturing Technology, 2010, 59(1): 37-40.

[13] Komata H, Kato Y, Takayama M, et al. Evaluation of greenhouse gas emissions and problems of the methods for the production of lumber, glued laminated timber and plywood[J]. Journal of the Hokkaido Forest Products Research Institute, 2010, 539: 1-5.

[14] Wilson J B. Life-cycle inventory of medium density fiberboard in terms of resources, emissions, energy and carbon[J]. Wood and Fiber Science, 2010, 42(5): 107-124.

[15] Wilson J B. Life-cycle inventory of particleboard in terms of resources, emissions, energy and carbon[J]. Wood and Fiber Science, 2010, 42(5): 90-106.

[16] Garcia R, Freire F. Carbon footprint of particleboard: A comparison between ISO/TS 14067, GHG protocol, PAS 2050 and climate declaration[J]. Journal of Cleaner Production, 2014, 66(2): 199-209.

[17] Hussain M, Naseem M R, Taylor A. Carbon footprint as an environmental sustainability indicator for the particleboard produced in Pakistan[J]. Environmental Research, 2017, 155: 385-393. 
[18] Newell J P, Vos R O. Accounting for forest carbon pool dynamics in product carbon footprints: Challenges and opportunities[J] Environmental Impact Assessment Review, 2012, 37(4): 23-36.

[19] 陈莎, 杨孝光, 李炏佩, 等. 中国纸产品全生命周期 GHG 排放 分析 [J]. 北京工业大学学报, 2014, 40(6): 944-949. [Chen S, Yang X G, Li Y P, et al. Life cycle GHG emissions of paper in China[J]. Journal of Beijing University of Technology, 2014, 40(6): 944-949. ]

[20] Tahara K, Shimizu H, Nakazawa K, et al. Life-cycle greenhouse gas emissions of e-books vs. paper books: A Japanese case study [J]. Journal of Cleaner Production, 2018, 189: 59-66.

[21] González-García S, Gasol C M, Lozano R G, et al. Assessing the global warming potential of wooden products from the furniture sector to improve their ecodesign[J]. Science of the Total Environment, 2011, 410-411: 16-25.

[22] Liu M, Li G Y. Carbon footprint assessment methods of wood furniture based on LCA[J]. Advanced Materials Research, 2014, 912-914: 1600-1602.

[23] Linkosalmi L, Husgafvel R, Fomkin A, et al. Main factors influencing greenhouse gas emissions of wood-based furniture industry in Finland[J]. Journal of Cleaner Production, 2016, 113: 596-605.

[24] 陈硕, 胡继梅, 沈乃强, 等. 强化木地板的 “碳足迹”计算分析 [J]. 木材工业, 2014, 28(2): 36-38. [Chen S, Hu J M, Shen N Q, et al. "Carbon footprint" calculation and analysis for laminate flooring[J]. China Wood Industry, 2014, 28(2): 36-38. ]

[25] Takano A, Pittau F, Hafner A, et al. Greenhouse gas emission from construction stage of wooden buildings[J]. Journal of the Institute of Wood Science, 2014, 5(4): 217-223.

[26] Chang Y S, Kim S, Son W L, et al. Evaluation of greenhouse gas emission for wooden house using simplified life cycle assessment tool[J]. Journal of the Korean Wood Science and Technology, 2017, 45(5): 650-660.

[27] 中华人民共和国国家林业局. 中国林业统计年鉴(2016)[M]. 北 京: 中国林业出版社, 2017. [The State Forestry Administration of the People's Republic of China. China Forestry Yearbook 2016[M]. Beijing: China Forestry Publishing House, 2017. ]

[28] 李晓平, 周定国, 于艳春. 利用生命周期评价法评价农作物秸 秆人造板的环境特性 [J]. 浙江农林大学学报, 2010, 27(2): 210216. [Li X P, Zhou D G, Yu Y C. Value environment characters of crop stalks based board with life cycle assessment[J]. Journal of Zhejiang Forestry College, 2010, 27(2): 210-216. ]

[29] Food and Agriculture Organization of the United Nations (FAO). FAO's Online Statistical Database[EB/OL]. (2019-01-10)[201901-23]. http://www.fao.org/faostat/en/\#data/FO/visualize.

[30] British Standards Institution (BSI). Publicly Available Specification 2050: 2008 Specification for the Assessment of the Life Cycle Greenhouse Gas Emissions of Goods and Services[S]. Lon- don: BSI, 2008.

[31] British Standards Institution (BSI). Publicly Available Specification 2050: 2011 Specification for the Assessment of the Life Cycle Greenhouse Gas Emissions of Goods and Services[S]. London: BSI, 2011.

[32] World Resources Institute and World Business Council for Sustainable Development (WRI/WBCSD). Product Life Cycle Accounting and Reporting Standard[S]. Washington DC: WRI/ WBCSD, 2011.

[33] International Organization for Standardization (ISO). ISO 14067: Carbon Footprint of Product- Requirements and Guidelines for Quantification and Communication[S]. Geneva: ISO, 2013.

[34] Nakano K, Ando K, Takigawa M, et al. Life cycle assessment of wood-based boards produced in Japan and impact of formaldehyde emissions during the use stage[J]. International Journal of Life Cycle Assessment, 2018, 23(4): 957-969.

[35] Wu P, Xia B, Wang X. The contribution of ISO 14067 to the evolution of global greenhouse gas standards: A review[J]. Renewable and Sustainable Energy Reviews, 2015, 47: 142-150.

[36] European Commission. Analysis of Existing Environmental Footprint Methodologies for Products and Organizations: Recommendations, Rationale, and Alignment[R]. Ispra: Institute for Environment and Sustainability, 2011.

[37] Jungmeier G, Werner F, Jarnehammar A, et al. Allocation in LCA of wood-based products[J]. International Journal of Life Cycle Assessment, 2002, 7(5): 290-294.

[38] FPInnovations. Product Category Rules (PCR) for Preparing an Environmental Product Declaration (EPD) for North American Structural and Architectural Wood Products[S]. Vancouver: FPInnovations, 2013.

[39] 中国林产工业协会. 中国人造板产业报告(精简版)[J]. 林产工 业, 2015, 42(11): 5-15. [China National Forest Products Industry Association. China's wood-based panel industry report (compact edition) [J]. China Forestry Products Industry, 2015, 42(11): 5-15. ]

[40] Pandey D, Agrawal M, Pandey J S. Carbon footprint: Current methods of estimation[J]. Environmental Monitoring and Assessment, 2011, 178(1-4): 135-160.

[41] Intergovernmental Panel on Climate Change (IPCC). 2006 IPCC Guidelines for National Greenhouse Gas Inventories[R]. Hayama: Institute for Global Environmental Strategies, 2006.

[42] 时兰翠. 木质材料加工过程碳储量变化研究[D]. 哈尔滨: 东北 林业大学, 2012. [Shi L C. Research on Carbon Sequestration Changes in the Processing Process of Wood Materials[D]. Harbin: Northeast Forestry University, 2012. ]

[43] 钱小瑜. 我国纤维板生产的木材原料状况分析 $[\mathrm{J}]$. 中国人造 板, 2009, 16(10): 8-10. [Qian X Y. Situation of fiberboard raw 
material supply in China[J]. China Wood-based Panels, 2009, 16 (10): 8-10. ]

[44] 张方文. 定向刨花板生命周期评价(LCA)及环境影响评价研究 [D]. 北京: 中国林业科学研究院, 2017. [Zhang F W. Research on Life Cycle Assessment and Environmental Impact Assessment of Oriented Strand Board[D]. Beijing: Chinese Academy of Forestry, 2017. ]

[45] 中华人民共和国国家统计局. 中国统计年鉴(2017)[M]. 北京: 中国统计出版社, 2018. [National Bureau of Statistics of the People's Republic of China. China Statistical Yearbook 2017 [M]. Beijing: China Statistics Press, 2018. ]

[46] González-García S, Berg S, Feijoo G, et al. Environmental impacts of forest production and supply of pulpwood: Spanish and Swedish case studies[J]. International Journal of Life Cycle Assessment, 2009, 14(4): 340-353.

[47] 张运明. 不同工艺生产䐂醛胶的单位产品综合能耗分析[J]. 中 国人造板, 2013, 20(8): 12-13. [Zhang Y M. Comprehensive energy consumption analysis of UF resins prepared via different process[J]. China Wood-based Panels, 2013, 20(8): 12-13. ]

[48] 张雄智, 王岩, 魏辉煌, 等. 特定农产品碳足迹评价及碳标签制 定的探索 [J]. 中国农业大学学报, 2018, (1):188-196. [Zhang X $\mathrm{Z}$, Wang $\mathrm{Y}$, Wei $\mathrm{H} \mathrm{H}$, et al. Assessment of carbon footprint for a specific agricultural product and discussion of carbon label designing[J]. Journal of China Agricultural University, 2018, (1):188196. ]

[49] 刘夏璐, 王洪涛, 陈建, 等. 中国生命周期参考数据库的建立方 法与基础模型 [J]. 环境科学学报, 2010, 30(10): 2136-2144. [Liu X L, Wang H T, Chen J, et al. Method and basic model for development of Chinese reference life cycle database of fundamental industries[J]. Acta Scientiae Circumstantiae, 2010, 30(10): 2136-2144. ]

[50］中华人民共和国国家林业局. LY/T 1529-2012 胶合板生产综合 能耗[S]. 北京: 中国标准出版社, 2012. [The State Forestry Administration of the People's Republic of China. Comprehensive Energy Consumption of Plywood Production[S]. Beijing: Standards Press of China, 2012. ]

[51] Athena Sustainable Material Institute (ASMI). A Cradle-to-Gate Life Cycle Assessment of Canadian Medium Density Fiberboard (MDF): 2013 Update[R]. Ottawa: Canadian Wood Council, 2013.

[52] Rivela B, Ma T M, Feijoo G. Life cycle inventory of medium density fiberboard[J]. International Journal of Life Cycle Assessment, 2007, 12(3): 143-150.

[53] Piekarski C M, de Francisco A C, Da L L, et al. Life cycle assessment of medium-density fiberboard (MDF) manufacturing process in Brazil[J]. Science of the Total Environment, 2017, 575: 103111.

[54] Puettmann M, Oneil E, Wilson J. Cradle to Gate Life Cycle As- sessment of U. S. Medium Density Fiberboard Production[R]. Washington: Final Report to the Consortium for Research on Renewable Industrial Materials, 2013.

[55] Wang S, Zhang H, Nie Y, et al. Contributions of China's woodbased panels to $\mathrm{CO}_{2}$ emission and removal implied by the energy consumption standards[J]. Forests, 2017, DOI: 10.3390/f8080273.

[56] Meil J, Bushi L, Garrahan P, et al. Status of Energy Use in the Canadian Wood Products Sector[R]. Vancouver: Canadian Industry Program for Energy Conservation, 2010.

[57] Kaestner D. Life Cycle Assessment of the Oriented Strand Board and Plywood Industries in the United States of America[D]. Knoxville: The University of Tennessee, 2015.

[58] Kouchakipenchah H, Sharifi M, Mousazadeh H, et al. Life cycle assessment of medium-density fiberboard manufacturing process in Islamic Republic of Iran[J]. Journal of Cleaner Production, 2016, 112: 351-358

[59] Silva D A L, Lahr F A R, Garcia R P, et al. Life cycle assessment of medium density particleboard (MDP) produced in Brazil[J]. International Journal of Life Cycle Assessment, 2013, 18(7): 1404-1411.

[60] 王丽, 周贤武, 王滋, 等. 基于生命周期评价的木质材料碳足迹 分析 [J]. 中国人造板, 2015, 22(6): 7-10. [Wang L, Zhou X W, Wang Z, et al. Analysis of carbon footprint in wood materials based on life cycle assessment[J]. China Wood-Based Panels, 2015, 22(6): 7-10. ]

[61] 胡广斌, 肖小兵. 我国中密度纤维板企业能耗水平分析[J]. 林 产工业, 2012, 39(3): 35-36. [Hu G B, Xiao X B. The energy consumption analysis of MDF production enterprises in China[J]. China Forest Products Industry, 2012, 39(3): 35-36. ]

[62] 张方文, 陈水龙, 张海孝, 等. 定向刨花板生产过程的生命周期 评价[J]. 木材工业, 2017, 31(3): 31-34. [Zhang F W, Chen S L, Zhang $\mathrm{H} \mathrm{X}$, et al. Life cycle assessment of oriented strand board production[J]. China Wood Industry, 2017, 31(3): 31-34. ]

[63] Smyth C, Rampley G, Lemprière $\mathrm{T}$ C, et al. Estimating product and energy substitution benefits in national scale mitigation analyses for Canada[J]. Global Change Biology Bioenergy, 2016, 9: 1071-1084.

[64] 张南, 李楠, 刘一, 等. 生态设计家具的碳足迹核算与减排效果 分析: 以木质家具为例 [J]. 生态学报, 2016, 36(22): 7235-7243 [Zhang N, Li N, Liu Y, et al. Calculation of the carbon footprint of eco-design furniture and measures for its mitigation: A case study of wooden furniture[J]. Acta Ecologica Sinica, 2016, 36 (22): 7235-7243. ]

[65] Sandin G, Peters G M, Svanström M. Life Cycle Assessment of Forest Products- Challenges and Solutions[M]. Cham: Springer, 2016. 


\title{
Carbon footprint and energy consumption based on life cycle assessment of wood-based panel industry in China
}

\author{
WANG Shanshan ${ }^{1,2}$, ZHANG Han ${ }^{2,3}$, YANG Hongqiang ${ }^{1,2,4}$ \\ (1. College of Economics and Management, Nanjing Forestry University, Nanjing 210037, China; \\ 2. Research Center for Economics and Trade in Forest Products, SFA, Nanjing 210037, China; \\ 3. Department of Economics and Management, Northwest A\&F University, Yangling 712100, China; \\ 4. Center for the Yangtze River Delta's Socioeconomic Development, Nanjing University, Nanjing 210093, China)
}

\begin{abstract}
Reducing greenhouse gas emissions (GHG) is an important measure to cope with climate change. Carbon footprint (CF) analysis is widely used to quantify greenhouse gas emissions of a product during its life cycle. Given that China has committed to decreasing its carbon dioxide $\left(\mathrm{CO}_{2}\right)$ emissions, the forestry sector has to make important contributions in this effort to mitigate climate change. China has become the largest wood-based panel producer and exporter worldwide. As the pillar of the forestry industry, evaluating carbon footprint and energy consumption of the wood-based panel industry is a vital part of environmental analysis of the forestry industry. Based on the ISO 14067 standard, this study quantified the carbon footprint of plywood, fiberboard and particleboard in China using a cradle- to-gate life cycle assessment approach. This study also evaluated the energy-saving potential of the wood-based panel industry in China by comparing the energy consumption in China and internationally. Finally, combined with the quantitative reduction effect of the improvement scheme, suggestions for reducing emissions and optimizing the market structure of the wood-based panel industry were provided. The results of this study show that fiberboard manufacturing produced the largest contributions to the emissions of greenhouse gases $(708.74 \mathrm{~kg} \mathrm{CO} 2 \mathrm{e})$, followed by particleboard $\left(410.79 \mathrm{~kg} \mathrm{CO}_{2} \mathrm{e}\right)$ and plywood (312.08 $\left.\mathrm{kg} \mathrm{CO}_{2} \mathrm{e}\right)$. During the life cycle, the raw material acquisition subsystem had the greatest impact on carbon footprint. The production and use of chemicals such as the ureaformaldehyde resin were the main sources of greenhouse gas emissions. The energy consumption of China's wood-based panel industry was higher than the requirements of international standards and could be reduced by $13.27 \% \sim 47.99 \%$. China's wood-based panel industry could potentially contribute to climate change mitigation in the future. In particular, as a substitute for fossil energy, using wood fuels could reduce the emission of greenhouse gases by $11.53 \% \sim 42.30 \%$.
\end{abstract}

Key words: wood-based panel industry; life cycle assessment; ISO 14067; greenhouse gas emissions; carbon footprint; energy consumption; China 